\title{
LAS VOCES DEL CHOGA: DISONANCIAS Y CONSONANCIAS ACERCA DE UNA ENFERMEDAD POPULAR ${ }^{213}$
}

\author{
Alvar JONES SÁNCHEz ${ }^{214}$ \\ Universidad de Castilla-La Mancha
}

Resumen: El choga es el nombre popular por el que se conoce un cuadro patológico infantil muy extendido en Guinea Ecuatorial. Más del 70\% de las madres interrogadas en la ciudad de Bata reconocían que alguno de sus hijos lo había padecido. Los saberes, representaciones y prácticas en torno al choga incluyen tanto elementos procedentes de la esfera popular como del contacto con el sector salud. Invitan en este sentido a repensar los vínculos entre medicina moderna y medicina tradicional, así como el carácter heterogéneo y dinámico de los saberes populares y biomédicos. Los nuevos mecanismos de transmisión de los saberes en el contexto urbano, los puntos de contacto con la esfera biomédica y las deficiencias del sistema sanitario, conforman un contexto en el que se revela el rol activo que desempeñan los individuos y colectivos en la producción y transformación de los saberes.

Palabras clave: Choga; Guinea Ecuatorial; saberes populares; discursos biomédicos; producción y transformación de saberes; itinerarios terapéuticos.

Aвstract: "Choga" is the popular name for a pathological set of symptoms which is widespread amongst children in Equatorial Guinea. When questioned if any of their children had ever suffered it, over $70 \%$ of mothers in Bata answered yes. Knowledge, representations and practices dealing with choga include both elements from the popular sphere and the health sector. In this sense, they encourage us to re-think the links between modern medicine and traditional medicine, as well as the heterogeneous and dynamic character of popular and biomedical knowledge. The new mechanisms of transmission of knowledge in the urban context, the points of contact with the biomedical sphere and deficiencies in the health system shape a context in which both

213 Este trabajo se enmarca en Proyecto de Investigación HAR2012-34599 titulado "Lo que sabemos, ignoramos, inventamos y deformamos acerca del pasado y el presente de Guinea Ecuatorial. Revisión crítica multidisciplinar y nuevas vías de investigación”.

214 Alvar.js@hotmail.com 
individuals and groups play an active role in the production and transformation of knowledge.

KeY WORDs: Choga; Equatorial Guinea; popular knowledge; biomedical discourses; production and transformation of knowledge; therapeutic itineraries.

\section{Introducción}

En Guinea Ecuatorial, la quema de cartón para ahuyentar mosquitos o el uso de antibióticos para la elaboración de un preparado medicinal pueden ser designados, por algunos interlocutores, como "medicina tradicional". La percepción contrasta con la utilización de elementos que la intuición situaría fuera de este campo. Las categorías medicina tradicional/medicina moderna (o científica) resultan reveladoras de la realidad social que pretenden describir, cuando en vez de imponerse a la misma, tratan de descubrir las referencias movilizadas por los individuos y colectivos. Son reveladores en la medida en la que constituyen para los agentes sociales mecanismos interpretativos que otorgan significados diferenciales a ambas dimensiones y guían las prácticas en consonancia.

Medicina moderna y medicina tradicional remiten a saberes y prácticas que no se definen tanto per se, en función de sus contenidos específicos. Su caracterización no puede pensarse fuera de la relación antagónica que mantienen y que otorga a cada una un ámbito y modalidades de acción determinados. El carácter "relacional" de la definición de "medicina tradicional" (Menendez, 1994) queda reflejado en otros términos utilizados por la población guineana para designarla, como "medicina país" o "medicina en fang", que permiten posicionarla frente a la "medicina de hospital" o "medicina de blancos". Esbozan fronteras flexibles entre la percepción endógena de los saberes, (los de aquí,) en referencia a prácticas pensadas como propias y situadas en el espacio étnico, nacional, o incluso africano, y lo exógeno (los de allí,) en referencia a aquellos asociados al occidente.

La dimensión relacional de los saberes permite abarcar tanto su influencia recíproca como las transformaciones que se operan en cada campo. Permite trascender una visión inmovilista de los saberes populares aún arraigada e influyente en las ciencias sociales. Los saberes populares ligados al acto terapéutico no constituyen un corpus fijo, permanencia o vestigio de un pasado a veces mitificado y 
de una relación privilegiada e inmutable con el entorno ecológico. Son flexibles, permeables, y en constante evolución.

El caso del choga, nombre popular por el que se conoce un cuadro patológico infantil muy extendido en Guinea Ecuatorial, es especialmente paradigmático en cuanto al dinamismo de estos saberes: En primer lugar, porque la emergencia relativamente reciente de la enfermedad en la nosología popular, pone de relieve la capacidad de la población para generar nuevos significados y mecanismos de respuesta frente a la enfermedad. En segundo lugar, porque los discursos sobre el choga incluyen de forma selectiva, elementos procedentes del sector salud, ilustrando el papel relevante de los profesionales de la salud en la evolución de los saberes populares. En tercer lugar, porque involucra en su tratamiento, elementos vegetales y manufacturados, (fármacos incluidos), confirmando la circulación y síntesis sincrética de los saberes. En fin, porque los saberes ligados al choga, no se enmarcan en el patrimonio exclusivo de un determinado grupo étnico o lingüístico, poniendo de relieve nuevos canales y modalidades de transmisión de los conocimientos y permanente resignificación de lo endógeno. Más allá de una etnografía descriptiva, centrada en la elaboración de un listado de saberes y creencias, es preciso abordar el dinamismo de los mismos y otorgar a los individuos y colectivos, un rol activo en su producción y transformación (Massé, 2006:15,16).

La antropología clásica, atraída por la densidad simbólica de enfermedades pertenecientes a nosologías mágico-religiosas, ha desatendido con frecuencia las enfermedades más comunes, que son sin embargo, las que marcan el cotidiano de los individuos y colectivos ${ }^{215}$. Ha participado de una visión distorsionada de la realidad de ciertas sociedades, en la que lo extraordinario aparentaría ser ordinario, la lectura sobrenatural de la enfermedad constituiría la norma, y la búsqueda del sentido del mal ${ }^{216}$ prevalecería sobre la búsqueda de una solución. Los principales comportamientos frente a la enfermedad de los guineanos son activados frente a procesos mórbidos percibidos como corrientes ${ }^{217}$. Los

215 E. Gillies, en un artículo precursor, ya alertaba en 1976 sobre el recurso abusivo desde la antropología de la interpretación sobrenatural de la enfermedad, aludiendo particularmente a E.E. Evans Pritchard y V. Turner (Gillies; 1976). Más recientemente, J.-P. Olivier de Sardan también invita a orientar el análisis hacia las manifestaciones más "prosaicas" de la enfermedad (Olivier de Sardan; 1994).

216 Según la expresión consagrada por Augé y Herzlich ( (1984).

217 Cabe señalar, que los inventarios producidos desde la tradición etnográfica clásica sobre los saberes populares relativos a la enfermedad no suelen mencionar las denominaciones adquiridas por el contacto con las instancias sanitarias biomédicas. En la actualidad, 
mecanismos de atención movilizados para los mismos incluyen tanto recursos asociados a la medicina moderna como a la medicina tradicional, sin involucrar por lo tanto etiologías y prácticas ligadas al mundo invisible y a las fuerzas ocultas que lo rigen.

En el 2011, visité varios espacios de terapia en Bata, capital de la región continental de Guinea Ecuatorial, con el fin de reflexionar acerca de las representaciones y modalidades de uso de los diferentes recursos existentes en la ciudad. Desde las primeras entrevistas, el choga se reveló como un mecanismo interpretativo muy extendido, relativo a un conjunto de síntomas mórbidos infantiles, que podía en ocasiones revelarse letal.

El choga constituye uno de los motivos más frecuentes de movilización de recursos extra-biomédicos en la zona de estudio. Su incidencia, más del 70\% de las madres interrogadas reconocían que alguno de sus hijos lo había padecido, contrasta con su total ausencia en la literatura etnográfica consultada.

De cara a aproximarse a las percepciones, experiencias y saberes generados en torno a la enfermedad, surgió la necesidad de seguir itinerarios y recoger relatos descriptivos e interpretativos de la población sobre la cuestión. Asimismo, parecía importante conocer la perspectiva de los servicios sanitarios en torno a la identificación popular de la enfermedad, para detectar los puntos de encuentro y desencuentro, consonancias y disonancias, entre las explicaciones populares y aquellas generadas desde el sector biomédico.

Los saberes y representaciones en torno al choga son ampliamente compartidos, sobre todo entre mujeres, preferentemente madres con varios niños bajo su cuidado. Las permanencias discursivas giran en torno a ciertos elementos recurrentes y con escasas variaciones que componen el núcleo duro, la unidad semántica de las representaciones sobre la enfermedad: el carácter infantil de la patología (afecta a los niños entre 0 y 3 años); su sintomatología extremadamente precisa; las limitaciones de los tratamientos recetados desde las instancias sanitarias biomédicas, percepción generalmente basada en una experiencia empírica; y la eficacia de las terapias endógenas a pesar de su heterogeneidad. En torno a

\footnotetext{
"paludismo", "tifoidea”, "anemia”, "fiebre amarilla”, son términos que marcan el cotidiano guineano, y que integran indiscutiblemente la nosología popular. En este marco, adquieren nuevos significados, algunos en consonancia y otros en disonancia, con los que se generan en el ámbito biomédico.
} 
estos saberes básicos sobre la enfermedad que componen el cuerpo estable de significados, gravitan dos ámbitos de conocimiento menos homogéneos, más flexibles y variables según el interlocutor, en torno a la etiología y origen de la enfermedad, y por otra parte, en cuanto a los procedimientos terapéuticos específicos a emprender, esto es, la composición y aplicación de los tratamientos endógenos.

En este sentido, y de acuerdo con estas diferentes vertientes que moldean los comportamientos frente al choga, trataremos en un primer lugar de definir el conjunto de síntomas que concurren a su identificación. Seguidamente, analizaremos los aspectos nominales y etiológicos que concurren a su clasificación. En tercer y cuarto lugar, abordaremos respectivamente los itinerarios en búsqueda de atención y mecanismos de respuesta endógenos que conforman el dispositivo terapéutico más o menos estable producido por los agentes sociales. En última instancia, abordaremos las diferentes voces que sobre el choga se generan desde el sector sanitario, y como esta enfermedad popular ilustra y cristaliza algunos de los desencuentros claves entre la población y los profesionales de la salud.

\section{PERSPECTIVAS POPULARES SOBRE EL CHOGA}

\section{El cuadro clínico popular del choga}

Las madres son quienes en primera línea, ya sea en el ámbito doméstico o extra-doméstico, gestionan los procesos enfermizos de los hijos, especialmente aquellos considerados benignos y que no requieren la movilización de recursos económicos, materiales y sociales importantes. Aparecen con frecuencia como las principales gestoras de los itinerarios terapéuticos de los menores, erigiéndose en las acompañantes e interlocutoras por excelencia en los diferentes espacios de terapia. Acumulan en base a su experimentación empírica en el cuidado de los demás, conocimientos y representaciones que proceden tanto del contacto con el sector salud como de los saberes populares y/o mágico-religiosos. Los saberes relativos al choga son principalmente detenidos por las mujeres, especialmente aquellas que tienen o han tenido varios niños bajo su custodia. Son quienes mejor informan acerca de los signos que concurren a su identificación. 
La descripción de los síntomas, o más bien la asociación de síntomas sobre la que se construye el cuadro clínico popular del choga es especialmente detallada en cuanto a la localización y signos característicos.

"Yo veo los efectos ahí [señala la garganta] y en el culo del bebé, porque cuando lo ves se nota fácilmente" (Cecilia, fang, 32 años, 4 hijos) ${ }^{218}$.

"Choga es cuando el caca de un nińo es como granizo de color amarillo, con un poco de agua.... Y esto le van enseñando color rojo, su culo" ( $\mathrm{M}^{\mathrm{a}}$ Gertrudis, Bisio, 23 años, un hijo).

"Algunos empiezan con la diarrea, aguda pero no tanto. Tienen unas bolas como calabaza. La calabaza que se cocina en la olla. Las heces del choga son amarillentas, con agua, mezclada con agua" (Judith, fang, 35 años, 5 hijos).

La conjunción de ambas manifestaciones, la irritación y enrojecimiento de partes específicas del cuerpo, y las características no menos específicas de las heces, conforman la base del cuadro clínico del choga. Las madres con mayor experiencia ofrecen mayor detalle:

"Aquí, toda esta parte, esta zona [señala las ingles y el cuello] se pone rojo rojo rojo como una herida así [...], como raspando. ahí, lo descubre de que es chogo. Los ojos pálidos al mirar así, como quiere dormir, sin comer, heces mal olor. Y dentro de esa diarrea, tiene granitos....así es" (Rosario, fang, 45 años, 10 hijos).

"Aquí [señala el cuello] y aquí [señala las ingles], rojo como una herida. Diarrea. Tú puedes ir en el hospital, te pueden inyectar, te pueden hacer .... Nada la diarrea no para. Así. Diarrea diarrea diarrea, sin terminar. Hay a veces que suele estar, si ya hay mucho dentro del cuerpo, le deja sin hablar. Puede estar aquí en la habitación, tu aquí en el comedor sin enterar. Pero el ahí llorando [...] Porque

218 Para cada cita textual de las madres se especificará la etnia, la edad y el número de hijos, ya que estas variables, especialmente las dos últimas desempeñan un papel importante en las representaciones, saberes y prácticas ligados al choga. Los nombres también serán indicados para facilitar al lector la identificación de cada interlocutor en las diferentes partes del texto. En referencia a los profesionales del sector salud, se han eludido estas informaciones. Las entrevistas han abordado otros aspectos ligados a su desempeño laboral y políticas sanitarias del país, por lo que se ha preferido, respondiendo a la solicitud de algunos, no facilitar elementos que faciliten su identificación. 
esa cosa del vientre... Te come ahí te come ahí....le puede matar" (Marcelina, ndowé, 38 años, 10 hijos).

El cuadro sintomatológico conforma el núcleo semiótico más estable del choga. El ano rojo, la irritación de la piel en los genitales, axilas y garganta, a menudo acompañado de heces granulosas y malolientes constituyen las principales características clínicas evocadas, pudiendo derivar hacia abundantes diarreas, la falta de apetito y un estado de debilidad generalizado en el que el infante puede llegar a fallecer. El choga se presenta como un sistema de signos, una configuración de síntomas fisiológicos y actitudinales. Su descripción, evolutiva, manifiesta una observación clínica atenta y concienzuda del cuerpo y comportamiento del infante.

\section{Origen y etiologías populares del choga}

La lógica nominativa de las enfermedades pertenecientes a los sistemas médicos antiguos de la zona responde generalmente a términos descriptivos vinculados a sus manifestaciones sintomáticas empíricas, (o a alguna de ellas, la que se considere más significativa,) o etiológicas en referencia a las causas presupuestas de la enfermedad (Mallart, 1977a:10; y Bibeau, 1978). El término "choga" (o "chogo", según las variaciones lingüísticas y dialécticas del país,) no tiene ningún significado manifiesto en los idiomas vernáculos por lo que como apunta una de nuestras interlocutoras, se trate de una nominación reciente e importada:

"Yo creo que viene de Camerún. Porque lo curan también con otros medicamentos. Como cigarrillo tradicional, como así verde. Lo curan las camerunesas. Así que yo creo que viene de Camerún ese nombre de choga. Porque en tiempos de Macias [1968-1978], yo vi muchas cosas ahí [...] Choga no estaba, no sonaba. No lo conocíamos en ese momento. Después de que Guinea se convirtió así en Guinea, Camerún, Gabón, ahí viene esa enfermedad. Es nuevo. No estaba antes.” (Rosario, fang, 45 años, 10 hijos)

El choga se desvincula en el contexto guineano, del "lazo orgánico" (Bibeau, 1978:83) entre el sistema nosológico, etiológico y nominal que caracteriza los sistemas médicos tradicionales antiguos, enmarcados étnica y lingüísticamente. Cabe en este sentido señalar el carácter transétnico del término. Es utilizado indistintamente por los diferentes grupos étnico-lingüísticos, sin diferencias 
sustanciales en cuanto a los significados movilizados. Las migraciones y contextos urbanos propician las interacciones y producción de sentidos compartidos.

Se han recogido sin embargo entre los ndowés, etnia minoritaria en la zona de estudio, variaciones, que en base a la ausencia de correspondencia directa del choga con enfermedades enmarcadas en la nosología ndowé, sitúan su emergencia en contexto fang:

"Anteriormente, mis abuelas en ndowé, lo llamábamos.... Bueno choga puedo decir que es una enfermedad de los fang, por eso ellos también lo saben curar. Porque una mujer fang es la que me dio esta medicina [le enseño como preparar la receta]. Los ndowés no lo sabíamos curar. Porque mis abuelos lo llamaban en ndowé mibuyá. Pero solo aquí [el cuello], rojo como una herida [...]. Pero anteriormente no mataba a un niño. Pero ahora ya mata." (Marcelina, ndowé, 38 años, 10 hijos).

Un ngengan ${ }^{219}$ ndowé que inscribe su saber en la tradición del grupo étnico al que pertenece, se muestra incluso reacio a utilizar el término:

"El nombre de choga no sé dónde viene, lo tienen ellos [los fang]. Solo lo vengo a oír hace poco. Parece que el abuelo lo llamaba Ngoyuá". (Magnegue, ngengan ndowé, 52 años).

Las variaciones ndowés giran en torno al contexto de emergencia de la enfermedad. Avanzan la hipotética relación o similitud con enfermedades pertenecientes a la nosología ndowé, y sitúan el origen de la expresión sintomatológica actual en contexto fang. Estas variaciones han sido recogidas en raras ocasiones y esencialmente en personas de cierta edad. En todo caso, no conllevan diferencias significativas en cuanto a la representación de la enfermedad, itinerarios y dispositivos terapéuticos implementados.

La etiología de la enfermedad se caracteriza por su inestabilidad semiótica ya que se han registrado no una sino varias teorías etiológicas. Asimismo, la respuesta "Yo no sé lo que produce el choga" (Marcelina, ndowé, 38 años, 10 hijos) es la más extendida, incluso entre las madres que se han enfrentado en algún

219 El ngengan es el terapeuta especializado en las afecciones ligadas al mundo invisible y a la brujería pero también suele intervenir en afecciones desligadas de la dimensión mágicoreligiosa. 
momento al choga y que conocen y utilizan mecanismos de respuesta pertenecientes a la terapéutica popular:

"Que es lo que causa el choga? No te puedo mentir, no lo sé. Solo sé que no se puede curar en el hospital o en la clínica. Si no se hace medicina tradicional puedes perder a tu bebé como broma”. (Cecilia, fang, 32 años, 4 hijos).

Cuando las causas sí son identificadas, se alude con frecuencia a la intrusión de elementos patógenos o al carácter innato de la enfermedad. Esta última percepción es asociada a muchas enfermedades infantiles.

"En fang el chogo es una enfermedad que los niños, los bebés nacen con esa enfermedad. Chogo. Y otras veces, eso de poner polvo.... ahora la sanidad ha descubierto de que antes de que bebé cumpla 3 meses no hay que poner polvo. Anteriormente lo hacían. Primer día después de bañar a bebé, le ungen eso polvos polvos polvos. Y ahí esa enfermedad reinaba aquí, chogo. Y en el hospital lo llaman infección. Ahí lo tratan como infección, con suero y ahí. (Rosario, fang, 45 años 10 hijos).

"Es una infección. Los polvos de talco por ejemplo. Cuando el niño es muy pequeño provocan una infección”. (Victoria,fang, 26 años, dos hijos)

"Hay algunos niños que nacen con esto. Y hay otros que nacen por el higiene de la madre. Que no sabe cuidar al niño, siempre sin braga, y todo esto entra, la suciedad". (Pilar, 26 años, fang, 2 hijos)

Destaca en primer lugar la frecuencia con la que las entrevistadas reconocen desconocer lo que causa el choga, lo que ya de antemano, cuestiona la supuesta necesidad del sentido del mal en las representaciones populares de la enfermedad. En segundo lugar, la mayor parte de las hipótesis etiológicas, cuando las hay, apuntan elementos patógenos exógenos (suciedad, polvos de talco) cuando la aparición de la enfermedad es situada cierto tiempo después del nacimiento. En tal caso, los cambios de hábitos en el cuidado de los niños, las informaciones erróneas emitidas desde el sector salud o la desatención de la madre son señalados. Cuando los síntomas se manifiestan desde los primeros días tras el parto, prevalece el carácter innato de la enfermedad. En tal caso, las causas permanecen de nuevo indefinidas. En ambos casos, prevalece la percepción "natural" de la enfermedad. 
Independientemente de las causas, las hipótesis formuladas más frecuentes suponen la presencia de "suciedad" en el vientre, lo que algunas incluso, reproduciendo voces sanitarias, denominan "infección”. Más allá de las manifestaciones externas del choga (la irritación del cuello, asilas y genitales, así como diarreas frecuentes y granulosas,) el foco patológico es ubicado en el vientre:

"Porque anteriormente no mataba a un nińo, pero ahora ya mata....porque esa cosa del vientre. Te come ahí, te come ahí...” (Marcelina,ndowé, 38 años, 10 hijos).

"El choga es una enfermedad de los niños, $\mathrm{Hmhm}$. Suele hacer diarrea, chupa por dentro de su vientre." (Irene, bisio, 28 años, 3 hijos).

"El niño aquí [el cuello] todo rojo, el culo.... Tu le miras al niño aquí en el cuello, rojo rojo rojo rojo. Ya lo ha cogido. Tu le ves que ya está, porque ya lo tiene dentro del vientre. Ya está comiendo. No tiene tiempo de hacer cacá. El vientre le duele porque ya está; o sea, ya le está picando el vientre." (Magnegue, ngengan ndowé).

Sobre 12 mujeres interrogadas, 5 confiesan no saber lo que causa el choga, aunque 3 de las mismas conozcan y utilicen remedios domésticos para tratarlo. 3 aluden a los polvos/infección. Una madre propone una respuesta similar aludiendo a "la suciedad que entra". Solo tres mujeres hacen referencia a otras hipótesis etiológicas, dos de ellas ligadas a la alimentación de la madre durante el embarazo, y una vinculando indirectamente el choga a las fuerzas ocultas.

\section{Teorías etiológicas minoritarias del choga}

En las siguientes explicaciones etiológicas, la mirada social detiene su atención en el comportamiento alimenticio de la madre.

"Me entero que también dicen que esos productos congelados que utilizan ahora. Los que ya han tardado y no se sabe cuando vinieron; si los comemos mientras estás embarazada.... Y esos alimentos pasan a los hijos, a las criaturas que llevamos. Por ejemplo si comes alas ahora, tú no puedes saber cuándo lo mataron. Y después lo traen aquí. (Alicia, fang, 24 años, dos hijos). 
"Comer cosas dulces, mucho azúcar durante el embarazo produce choga" (Magdalena, bubi, 39 ańos, 5 hijos).

La asociación del choga con las prácticas alimenticias de la madre no ha sido recogida con frecuencia, y es a menudo presentada de forma hipotética ("me entero que", "también dicen que"). Tampoco implica variaciones significativas en la búsqueda de atención y puesta en marcha de respuestas terapéuticas domésticas que detallaremos más adelante.

En ciertos discursos, el punto de anclaje del choga en el vientre facilita su puesta en relación con otras patologías pertenecientes a los marcos nosológicos más antiguos de los grupos étnicos de la zona, también localizadas en el vientre como el okákara ${ }^{220}$ y el $c_{h i t^{221}}$. Estas patologías ${ }^{222}$, especialmente la primera, están a menudo relacionadas con el mundo invisible. Uno de los discursos recogidos, sugiere una posible graduación, una evolución progresiva en términos de gravedad (chogalokkakaralchit), asociando cada etapa a una franja de edad específica. Como explica Adela, la vinculación del choga con el mundo invisible, sigue sin ser etiológica, sino una derivación, una evolución posible de la enfermedad:

"Cuando es de esta edad [muestra su niño de 4 años] ya tiene okakara. Okakara quiere decir la brujería ya le ha tocado su evú. Se mueve toda la barriga, empieza a llorar, le pica dentro, y eso fácilmente se puede morir [...] Eso también lo hace la gente mala. Cuando saben que esa pequeña [muestra una niña de unos cuantos meses] tiene eso de choga, le empiezan a hacer como ellos mismos lo

220 En fang, Okákara significa literalmente "pequeño cangrejo". Alude a la activación por el brujo del evú, poder vinculado a la brujería, ubicado en el vientre del niño.

221 En fang, el chit (animal) también es llamado "djom abum" que significa literalmente "algo en el vientre". La sintomatología asociada responde a la inflamación del bazo, por lo que es frecuentemente traducida por "bazo" en español. En términos biomédicos, es generalmente designado como esplenomegalia infantil. El chit es a veces relacionado con alguna infracción social de la madre, y en menor medida con la acción de los brujos, tal y como ya señalaba Mallart (1981:162). No obstante, muchos entrevistados consideran hoy que es una enfermedad "natural" sin ningún vínculo con el mundo invisible. Una apreciación probablemente relacionada con el contacto continuado con las estructuras sanitarias y con los tratamientos antipalúdicos con efectos notables sobre la esplenomegalia vinculada al paludismo.

222 Los marcos nosológicos de las etnias minoritarias de la zona, ndowé y bisio, comparten entre sí y con los fang muchas similitudes. Los interlocutores consultados suelen generalmente establecer las siguientes equivalencias nominales, ligadas a sus propios marcos nosológicos: Evusu (ndowé) y Gimbo (bisio) respecto al okakara, y Ebanda (ndowé) y Quechiri (bisio), respecto al chit. 
suelen hacer para que se muera. Se lo hacen de otra forma para que la niña sufra, sufra y se convierta en chit." (Adela, fang, 23 años, 2 hijos)

Un ngengan, reconociendo el "origen biológico" del choga, recuerda que el brujo tiende en ocasiones a ocultar sus ataques desde el mundo invisible, tras una enfermedad "normal", de cara a confundir la víctima, retrasar la adecuada respuesta terapéutica y propiciar un desenlace fatal. Otra ngengan ha situado el choga en el terreno de la transgresión social, aludiendo a la responsabilidad del padre, por mantener simultáneamente relaciones sexuales intra y extra-matrimoniales durante el embarazo de su legítima esposa.

Las teorías etiológicas que aluden al posible disimulo de las acciones de los brujos o que ponen en relación el orden social con el orden fisiológico del recién nacido son enunciados de cara a legitimar la intervención del ngengan, generalmente poco solicitado frente a este proceso patológico. Disponen de escaso arraigo en las representaciones populares de la enfermedad y han sido negadas por la mayor parte de nuestros interlocutores, que inciden en el carácter prosaico del choga, desvinculándolo de cualquier manifestación sobrenatural.

El carácter infeccioso del choga, los polvos de talco, la vinculación con otras enfermedades pertenecientes a la etiología endógena antigua, la alimentación de la madre durante el embarazo, la percepción del choga como preludio del okakara o del chit, o la transgresión del orden social, constituyen una constelación de explicaciones, algunas incluso exclusivas entre sí. La riqueza semántica en torno a la etiología del choga, el carácter flotante del significante, (también propiciado por la designación de la enfermedad con un sustantivo sin significado manifiesto en las lenguas vernáculas,) cuestiona la supuesta homogeneidad de las representaciones que la antropología presta a veces a los saberes populares.

\section{Itinerarios terapéuticos del choga}

Los itinerarios ligados al choga permiten aprehender el carácter empírico de los conocimientos que sobre él se generan así como los mecanismos que derivan hacia la sistematización de la respuesta a vocación terapéutica. A continuación, exponemos 7 itinerarios: 
1\%/ Victoria (fang, 26 ańos, dos hijos) acompaña a su hijo de tres meses, ingresado en el servicio de pediatría del Hospital General de Bata. Tiene paludismo. Asimismo, muestra irritaciones en las ingles por lo que le han recetado una pomada. Su hermana, en una visita al hospital, le ha dicho que el niño tiene choga. A los tres días, el niño es dado de alta en el hospital. Victoria considera que el paludismo ha sido curado, y sigue aplicando la pomada. No obstante, al cabo de tres días, las marcas rojas que ella asocia con el choga aún permanecen a la vista. Acude a su hermana que según dice "lo sabe curar muy bien". Victoria explica que "el choga se cura en el hospital pero no termina".

2\%/ Trifonia (fang, 19 años, 1 hijo) acude a la consulta del hospital la Paz (un complejo sanitario privado) con su hijo de un año y medio. Tiene fiebres altas e intermitentes así como el ano rojo y heces granulosas. Más allá de los antipalúdicos, le recetan "micostatin". Trifonia también lo llama "medicina de choga". A la semana, y frente a la persistencia de los síntomas asociados con el choga, su madre la manda con su hijo al pueblo para tratarlo.

3\%/ Pilar acudió con su primogénito de apenas cuatro meses al hospital:

"El médico me recetó esto de micostatine, unos comprimidos y un medicamento que es hepadif, es un jarabe así. Empecé a darle. No funcionó. Empezó a cagar más con sangre y todo. Una mujer, ella también tenía su niño aquí [en el hospital] me dijo que era choga. Me receto algunos medicamentos tradicionales. Ve a coger esto de palmiste, y unos comprimidos de tetraciclina.... Si tu le das unas hierbas ahí [mesep]... esto se terminó" (Pilar, fang, 26 años, 2 hijos).

4\%/ "Anteriormente estuve en el hospital. Me dieron Nistatine, pomada y jarabe. Eso no se curaba. Una semana pero no se curaba. Es cuando ya le estaba saliendo la herida aquí [señala las ingles], todo de color rojo. La amiga de mi mamá me dijo que esto es choga, es la que vino a descubrirlo cuando mi mamá estaba en el pueblo. Es cuando fui donde una mujer [...] los ndowés ya curan eso. Una mujer ndowé vive en los Cocos también. Se llama Tia Mari. Es la que curó mis niños [...]. Se mejoró" (Magdalena, ndowé, 20 años, 1 hijo).

5\%/ "Mi primogénito estuvo enfermo, y tuvo eso de choga. Mi abuela me dijo que esa enfermedad no se cura en el hospital o en la clínica porque siempre se tiene que tratar tradicionalmente, por eso le llevé donde una mujer que sabía curar el choga. Lo curaron y ya está bien. No volvió a enfermar [...]. No se puede 
curar en el hospital o en la clínica. Si no se hace la medicina tradicional puedes perder a tu bebé como broma." (Cecilia, fang, 32 años, 4 hijos).

6\% "Los primeros días que yo no lo sabía, fui al hospital. Una mujer sí que me detectó esto, yo tenía el niño así, ya le había salido aquí todo [señala las ingles]. Y el niño estaba así desnudo. Y esa mamá pasaba. Como donde yo vivía allí en mi barrio, la gente pasaba como pasan aquí en mi puerta. Y esa mujer me miró así, dice: ipero cómo! Si eso es lo que se llama choga. ¿Choga? Dice sí. ¿Qué es lo que significa choga? Me dice esta enfermedad. Dice vamos que te enseño la cura. Mi propia vecina. Desde ahí, yo ya curo mis niños cuando esto sale." (Marcelina, ndowé, 38 ańos, 10 hijos)

7\%/ "Mi hijo tenía choga [...]. Aquí en el hospital receta que me dieron. Me daban jarabe de...Nistatine. Aquí en el hospital, y pomada también. Yo le llevaron en casa. Y después de ahí, ella no había mejorado. Y después de ahí, yo tenía que irme en la curandería en esa misma hora. Allí terminó.” (Flora, fang, 32 ańos, 4 hijos).

Se pueden multiplicar indefinidamente los ejemplos, el patrón del recorrido suele repetirse en la mayor parte de los casos. Inicialmente inexpertas al tratarse del primogénito o porque ningún otro de sus hijos ha padecido la enfermedad, los síntomas, meros indicios de una enfermedad, no constituyen un cuadro clínico identificado. A menos que como en el caso $5^{\circ}$, alguien del entorno cercano del niño, en este caso la abuela, establezca el diagnóstico desde el principio, y prescriba algún recurso endógeno, las madres acuden generalmente al hospital o al centro de salud ${ }^{223}$. Ante la persistencia de los síntomas y el desamparo de la madre, un nuevo actor, un familiar (hermana, cuñada, abuela), una vecina o incluso una enfermera del hospital suele "desvelar" el diagnóstico a la madre. En algunos casos, es esta misma persona quién aplicará el tratamiento o quién enseñe a la madre como prepararlo y aplicarlo. En otros, se acudirá a otra persona, generalmente del entorno familiar o vecinal cercano, conocida por saber tratar el choga.

Varias madres entrevistadas son capaces de nombrar los fármacos generalmente recetados desde las instancias sanitarias, (micostatin, o nistatina según la designación de su principio activo,) y las modalidades asociadas de aplicación (por vía oral, en jarabe y/o pomada). Conocen y han experimentado el

223 Las clínicas u hospitales privados son menos solicitados por razones económicas. 
dispositivo terapéutico activado desde las estructuras sanitarias frente al cuadro sintomatológico que ellas asocian con el choga. Consideran no obstante que los tratamientos desde allí implementados, son insuficientes; "calman" en el mejor de los casos, o pueden incluso empeorar el estado de salud del infante. En todo caso, "no terminan" con la enfermedad.

La primera vez que las madres se enfrentan a la enfermedad, la tardanza en vislumbrar señales de mejora con el tratamiento impulsado desde las instancias sanitarias constituye a menudo un factor clave en la producción de un nuevo diagnostico desde el entorno, y la consideración de recursos alternativos. En los casos sucesivos, ya sean otros hijos o niños del entorno cercano, las madres dispondrán, en base a su propia vivencia, de los elementos necesarios para diagnosticar, orientar y en su caso tratar la patología.

Sobre un total de 30 madres entrevistadas en el Hospital General de Bata (20) y en el centro de salud de SOS (10), el 73\% (22) han confirmado que al menos uno de sus hijos había tenido choga. El 18\% de las mismas (4) ha recurrido directamente a un recurso endógeno donde han encontrado, según su apreciación, una solución satisfactoria. El 82\% (18) ha acudido la primera vez a alguna instancia sanitaria (centros de salud, hospitales, clínica privada). Solo el $17 \%$ (3) de estas dice haber encontrado una solución definitiva en estos servicios. Las demás, el 83\% (15) han utilizado tras el paso por los servicios sanitarios, métodos endógenos, logrando, según su apreciación, resultados positivos en el 93\% (14) de los casos. El itinerario más dramático que hayamos registrado, y que corresponde a esta mínima franja $(7 \%)$ en la que prevalece la percepción de fracaso de los mecanismos endógenos, es el de Josefa (fang, 24 años, 1 hijo):

Su hija de 16 meses empezó a enfermar al poco tiempo de quedarse de nuevo embarazada. Tenía vómitos y diarreas. Josefa piensa en un primer momento que su hija está enferma porque está tomando la leche que ya no le corresponde a ella, sino al futuro bebé por nacer. Josefa acelera por lo tanto el destete. Frente a la persistencia de los síntomas, acude al hospital. Después de tres días de ingreso, y a la vista de que los síntomas no remiten, sus familiares le dicen que se trata de choga. Recomendada por su entorno familiar, lleva su hija a una mujer del vecindario que suele curar el choga. Le da un tratamiento con plantas que aplica durante un mes. La niña se hace cada vez más flaca y más débil. Josefa decide abandonar el tratamiento, y vuelve al hospital. Al segundo día, y tras los análisis, 
los médicos le dicen que la niña tiene VIH sida. Josefa no lo entiende, porque la nińa ha nacido en el hospital. Y porque no le han dicho nada hace un mes. Le invitan a hacerse también la prueba...

Dado el tamaño de la muestra, estas estadísticas son difícilmente extrapolable al conjunto de la población. No obstante, sí concuerdan con la alta incidencia de las enfermedades diarreicas infantiles en el país ${ }^{224}$. Por otra parte, también dan cuenta, no tanto del éxito o fracaso de las alternativas solicitadas, sino de la percepción de éxito o fracaso de las mismas. Los itinerarios registrados en el trabajo de campo y solventados según apreciación de las madres, desde la terapéutica popular, constituyen la amplia mayoría de los casos. La alta frecuencia de fracaso prestada al sector sanitario, y resoluciones exitosas conferidas a las respuestas endógenas se arraigan en la experimentación empírica de las madres, otorgando a sus ojos, una indiscutible legitimidad a los itinerarios aprendidos, que frente al choga, finalizan fuera de los cauces sanitarios institucionales.

\section{Tratamientos populares del choga}

Pocas madres consideran satisfactoria las respuestas terapéuticas generadas por las instancias sanitarias. También es preciso señalar, que entre las que sí las consideran determinantes, y que en una primera ocasión han solventado la patología en el hospital, algunas reconocen prescindir de la consulta en ocasiones ulteriores. Adquieren directamente en algún punto de venta de medicamentos el tratamiento recetado la primera vez en consulta. Logran así ahorrar el coste y tiempo requeridos por una nueva consulta.

Generalmente, la percepción de fracaso asociado a los tratamientos biomédicos y el carácter "natural" del choga lo sitúa entre las afecciones que se tratan prioritariamente en el ámbito doméstico o vecinal. El ngengan, el terapeuta especializado en las afecciones vinculadas a la brujería y a las fuerzas ocultas es poco solicitado. Cuando lo es, la respuesta terapeuta no difiere mucho de aquellas

224 La encuesta demográfica y de salud realizada en 2011 en Guinea Ecuatorial revelaba que el porcentaje de niños menores de 5 años con diarrea en las dos semanas que precedieron la encuesta giraba en torno al 20\%. A pesar de los escasos datos fiables en Guinea Ecuatorial, existe un amplio consenso entre los diferentes actores sanitarios a la hora de designar las enfermedades diarreicas agudas (EDAs) como la segunda causa, tras el paludismo, de mortalidad infantil en el país. Constituye por lo tanto uno de los principales desafíos sanitarios. 
puesta en marcha en el ámbito domestico, y como aquellas, no suele implicar elementos rituales.

En realidad, no hay diferencias significativas en cuanto a las representaciones del choga entre el ngengan, detentor de saberes específicos y los saberes populares compartidos por la población: operan las mismas descripciones sintomatológicas, y aluden generalmente a las mismas teorías etiológicas (o en su caso, ausencia de las mismas). Comparten, aunque con las excepciones antes mencionadas, la percepción de la enfermedad en términos "naturales". Recurren cuando saben tratarlo, a una terapéutica basada en preparaciones domésticas exentas de cualquier elemento mágico-ritual. Existe respecto a la enfermedad, el mismo reparto sexual del saber entre los bingengan ${ }^{225}$ y los individuos y colectivos que no disponen de saberes terapéuticos especializados: las mujeres, dedicadas al cuidado de los hijos son las principales detentoras de los saberes y representaciones sobre el choga. La mayoría de los bingengan hombres preguntados reconocen no tratarlo.

El tratamiento del choga se inscribe de lleno en la terapia popular. No requiere los conocimientos del especialista, sino que su preparación y aplicación está al alcance de todos. Son generalmente mujeres con varios niños a su cargo quienes disponen de estos saberes, quienes los utilizan en el marco de su entorno familiar y vecinal, y quienes los difunden en estos mismos círculos sociales. Algunas mujeres son conocidas en sus respectivos barrios por saber curar el choga y son solicitadas con más frecuencia. En estos casos las transacciones económicas suelen ser poco relevantes y corresponden con frecuencia a la voluntad.

El siguiente listado es solo una muestra de la diversidad de prácticas terapéuticas populares recogidas ligadas al choga.

$1^{\circ}$ ) Se vierte en agua una piedra de kawan y cuatro cápsulas de tetraciclina. Se hierve en agua. Se deja reposar hasta que esté templado. Se aplica en lavativa dos veces al día. A medida que van remitiendo los síntomas se puede aplicar una vez al día. El tratamiento puede durar hasta tres meses para ser definitivo.

$\left.2^{\circ}\right)$ Verter una capsula de tetraciclina en aceite negro de palmiste. Añadir mesep en decocción y una gota de colonia. Aplicar una cuchara en lavativa tres veces al día.

225 Plural de ngengan. 
30) Se vierten dos cápsulas de tetraciclina y una piedra de aluán en el zumo de dos limones. Se aplica una cuchara en lavativa por la mañana antes de comer y por la noche antes de dormir.

40) Se vierten dos cápsulas de tetraciclina en aceite negro de palmiste. Se aplica una cuchara en lavativa mañana y tarde.

$5^{\circ}$ ) Se vierte el zumo de medio limón y dos gotas de petróleo en un litro de agua. Se ańaden hojas de bambucha (la hoja de la yuca hervida) machacadas. Se filtra y aplica la decocción en lavativa mañana y tarde. Su utiliza un tapón de botella para dosificar. Uno para cada toma. Se puede utilizar el tratamiento de forma preventiva una o dos veces al mes para evitar recaídas.

60) Se vierten dos cápsulas de tetraciclina y la corteza del árbol del mango en agua. Hervir y aplicar templado en lavativa.

70) Se vierten hojas de papaya, y la corteza del árbol del mango machacadas en agua. Se ańade zumo de limón y el contenido de cuatro cápsulas de tetraciclina. Se hierve. Se aplica la decocción en lavativa, mańana y tarde.

80) Hervir la corteza del arbol Akeng Elé en agua. Aplicar la decocción en lavativa mańana y tarde.

9o) Hervir la corteza del árbol del mango en agua. Aplicar la decocción en lavativa mańana y tarde.

$\left.10^{\circ}\right)$ Quemar la cascara del "plátano marrón", mezclar las cenizas con aceite negro de palmiste. Hervir en agua y aplicar en lavativa dos veces al día, y frotar el cuerpo del niño 226 .

Desconcierta la heterogeneidad de las prácticas terapéuticas asociadas a una misma patología. No se han registrado dos tratamientos idénticos a lo largo de las entrevistas. La mayor parte de los componentes aparecen en un solo tratamiento

226 En algunas familias, el tratamiento puede prolongarse de forma preventiva reduciendo la periodicidad del mismo durante varias semanas o meses, e incluso hasta el segundo año del niño. 
$\left(\right.$ Kawan $^{227}$, mesep ${ }^{228}$, colonia, aluan ${ }^{229}$, petróleo, bambucha ${ }^{230}$, hojas de papaya ${ }^{231}$, corteza del arbol akeng éle ${ }^{232}$, cascaras de "plátano marrón" $\left.{ }^{233}\right)$. Tres ingredientes aparecen en tres recetas (aceite negro de palmiste ${ }^{234}$, zumo de limón ${ }^{235}$, corteza del árbol del mango ${ }^{236}$ ). Solo uno, la tetraciclina, es utilizada en más de la mitad de los preparados.

Detengámonos en las principales recurrencias. En primer lugar el método de aplicación: la lavativa es una práctica extremadamente difundida en Guinea Ecuatorial. Constituye el procedimiento terapéutico popular más generalizado tanto en nińos como en adultos para "limpiar la suciedad dentro del vientre".

"Cuando la barriga del niño tiene suciedad, podemos dar lavativa" (Susana, fang, 26 años, 2 hijos).

"Cuando mi hijo durante 3 o 4 días no caca bien, su barriga está hinchada. Yo cojo algunas hierbas, como hierba de $\mathrm{Ndole}^{237}$, que es amargo, que cocino. Y lo hago con agua, lo filtro así, y se hace lavativa." (Irene, bisio, 27 años, 3 hijos)

Se asocian las enfermedades ligadas al vientre, a la intrusión de elementos extraños. El objetivo manifiesto del tratamiento del choga es "sacar", "hacer salir", "evacuar" la suciedad localizada en el vientre:

"Tu coges peladura de mangueña [árbol del mango]. Lo metes en el fuego con agua. Se termina de hervir. Tienes que coger pomme [pera de goma para

227 No identificado. Según la descripción recogida, se trata de un mineral de color negro que se deshace en el agua.

228 Ocimum viride Willd.

229 No identificado. Según la descripción recogida, se trata de un minral blanco o transparente que se deshace en el agua.

230 Hojas de Yuca o Manihot esculenta según su identificación botánica.

231 Carica papaya.

232 No identificado.

233 No identificado.

234 El aceite de pepita de palma se obtiene rompiendo la nuez de palma, el hueso del fruto de la palmera de aceite (Elaeis guineensis). Es preciso diferenciarla del aceite de palma, de color naranja, obtenida prensando los frutos de palma.

235 Citrus aurantifolia.

236 Mangifera indica.

237 Vernonia amygdaline. 
enemas] y lo metes al niño. Se saca esto. Lo que tiene en su vientre, tiene que salir todo eso. Eso es lo que cura el choga" (Maja, fang, 48 años, 4 hijos).

A pesar de la diversidad de los componentes involucrados, se presta a la mayoría de los mismos, cualidades (astringentes, laxantes, purgativas, digestivas, eupépticas) directamente ligadas a mejorar el funcionamiento del vientre. El mesep muestra evidencias de actividad antiséptica y laxante. La corteza del árbol del mango tiene propiedades astringentes. Es utilizado con frecuencia para aliviar el dolor de vientre. Es probablemente el efecto antiséptico del limón lo que motive aquí su empleo, aunque sus propiedades astringentes también pueden explicar esta elección. La Bambucha u hojas de yuca son a veces utilizadas en infusión por sus propiedades antihelmínticas contra los gusanos. Las hojas de papaya son utilizadas con frecuencia en decocción como eupéptico y purgativo. Los tratamientos movilizan por lo tanto las propiedades prosaicas (supuestas o confirmadas,) de los ingredientes sin apelar a virtudes invisibles, como protección por ejemplo frente a un ataque en brujería. En este sentido, también es preciso recalcar, que ninguno de los tratamientos registrados contempla elementos rituales.

\section{El uso de la tetraciclina en los tratamientos populares}

La recurrencia más significativa en el tratamiento del choga, es el vaciado del contenido de las cápsulas de tetraciclina, un antibiótico de amplio espectro, en la solución aplicada en lavativa. Aparece en más de la mitad de las respuestas terapéuticas populares ${ }^{238}$, aunque con variaciones importantes en la dosificación (de una a cuatro cápsulas). El carácter biomédico del principal agente activo del preparado no altera la percepción "tradicional" del remedio, su pertenencia a la farmacopea endógena, manifestada por todos los entrevistados. No son los objetos involucrados los que confieren el carácter "tradicional" o no de las prácticas terapéuticas, sino su uso y articulación en un contexto determinado y el significado que adquieren en el mismo.

Los saberes populares son una producción sincrética y flexible. Evolucionan alimentándose de fuentes diversas, reapropiándose elementos en principio exógenos que dan cuenta de la permanente interacción y síntesis de los diferentes

238 Las tres últimas recetas recogidas más arriba, nos han sido facilitadas por 3 bingengan. Ninguno de ellos utiliza tetraciclina, o reconoce hacerlo. 
saberes médicos. Los procesos de hibridación en el campo terapéutico han sido analizados desde el punto de vista de los conocimientos, estrategias curativas y cuadros clínicos. En menor medida desde el punto de vista de los objetos.

La tetraciclina, como otros productos manufacturados ${ }^{239}$ se ha erigido como un elemento clave en numerosas prácticas terapéuticas populares en Guinea Ecuatorial ${ }^{240}$. La existencia de un sustantivo en fang para designarla -fós ésé okuan-manifiesta su habilitación en el espacio terapéutico popular. Significa literalmente "la llaga ${ }^{241}$ no es enfermedad". El calificativo deriva de la práctica extendida y conocida según la cual se aplica el contenido de la cápsula en llagas especialmente lentas en cicatrizar. Responde a nuevos usos y significados asociados al medicamento, estructurados fuera del ámbito biomédico. La nominación popular en lenguas vernáculas de fármacos manufacturados ha sido observada y relatada en otras latitudes. En el sur de Camerún, las ampollas de ampicilina son apodadas "fol kodogo", literalmente, y según las etimologías, "caza herida" o "caza diarrea" (Monteillet, 2005: 75). Jaffré recoge en Bamako no menos de 23 medicamentos con sus correspondiente designación popular, aludiendo a la "integración cognitiva de los saberes biomédicos" (Jaffré, 1999:4,5)242. No obstante, a diferencia de la asociación sistemática y exclusiva entre un producto y unos síntomas determinados, supuestamente inducida según Jaffré por el nombre atribuido, la tetraciclina mantiene diferentes modalidades de uso en el ámbito popular. A las dos ya mencionadas, se suma el hábito recogido en algunas familias, de diluir el contenido de las cápsulas en coca-cola para aliviar ciertos dolores de vientre con estreñimiento.

239 La colonia o el petróleo por ejemplo, también integran algunas preparados para el choga. El uso del petróleo ha sido recogido en numerosos remedios caseros. Según algunos interlocutores, su uso, junto a otros ingredientes como la hoja de limón y el aceite de palmiste, era muy extendido frente al sarampión (olará en fang) en los ańos 70-80 del siglo pasado. Con una parte del preparado se bañaba al niño y la otra era aplicada en lavativa.

240 Prácticas similares han sido observadas en otras latitudes. Odina Sturzenegger por ejemplo, trabajando entre las poblaciones criollas de argentina, recoge el uso de grasa de motor, tinta o fósforos de cerilla en la elaboración de remedios percibidos como tradicionales (1999:279).

241 En referencia a las úlceras de la piel.

242 Véase también Touré, quién recoge diferentes nominaciones locales de la tetraciclina entre diferentes grupos étnicos en Mali. Es llamada Mousrewil entre los moros ("la que tiene el pequeño pantalón", en referencia a la cabeza roja de la cápsula) o kunbilenni en bambara (cabeza roja) (Touré, 2005: 280). 
El caso de la tetraciclina (fós ésé okuan) revela la capacidad de los individuos y colectivos para resignificar objetos y prácticas dando pié a su reapropiación y plena integración en la dimensión popular de los saberes. El recorrido de la tetraciclina se opera del "conocimiento ilustrado" a "las creencias locales", según el título del artículo de Mauricio Nieto Olarte. En el mismo, describe los procesos de recolección de los españoles en América en el siglo XVIII, de los conocimientos de las plantas medicinales de los "hierbateros" indios de Perú, y su conversión a la farmacopea universal mediante la nominación y clasificación a la luz de la doctrina médica europea. "La función que tiene la taxonomía como un mecanismo de traducción y apropiación de las prácticas locales a una ciencia ilustrada" (Nieto Olarte ,2000:94) funciona aquí en sentido inverso recordándonos que todo saber y objeto adquiere credibilidad y sentido en el contexto local.

\section{Incidencia y sistematización de la respuesta popular}

La alta incidencia del cuadro sintomatológico del choga es un factor determinante en los saberes, representaciones y prácticas asociadas, ya que ofrece a las madres un material de observación empírico denso. Da pié a una descripción detallada de los elementos invariables de la enfermedad y permite distinguirlo de otros procesos patológicos. Según aquellos que saben, resulta por lo tanto "muy fácil saber cuando el niño tiene choga". La recurrencia de la configuración específica de los síntomas confluye hacia un diagnóstico generalmente unívoco y socialmente compartido.

La alta incidencia de la enfermedad también la sitúa de lleno en el terreno de las afecciones comunes. La enfermedad no destaca por su carácter singular, propicio a las lecturas persecutoras. Alcanza a todos o casi todos, desvinculándola de los mecanismos selectivos de la brujería (Olivier de Sardan, 1994: 40). Desde el punto de vista etiológico, a pesar de las variaciones, permanece un tronco semántico común en torno al carácter "natural” del choga y a su localización en el vientre, de la cual derivan las demás manifestaciones sintomatológicas de la enfermedad.

Su definición no apela a estructuras simbólicas densas. Al preguntar "que es el choga", prevalece una descripción de una configuración determinada de síntomas. Respecto a las causas, el desconocimiento declarado por la mayoría de los entrevistados, y el carácter hipotético de los enunciados de otros, revela la 
escasa relevancia del origen del mal para la puesta en marcha de mecanismos de respuestas pautadas y normalizadas. No prevalece tanto la búsqueda de sentido, sino más bien la construcción de un saber empírico sobre la enfermedad de cara a controlar e incidir sobre el proceso patológico. La pregunta que guía los itinerarios terapéuticos no es tanto el "de que se trata" sino el "como se trata".

En la mayor parte de los casos registrados (el 82\%) la primera respuesta contemplada por las madres en la primera vivencia vinculada al choga ha sido el hospital o los centros de salud. Algunos casos patológicos similares, solventados en el hospital probablemente no sean identificados como choga ya que el fracaso de la respuesta terapéutica impulsada desde el mismo participa en muchos casos del primer diagnóstico del choga. En todo caso, lejos de cierto conformismo social, la mayor parte de las vivencias asociadas al choga ponen de relieve la evolución y sistematización de la respuesta de las madres en base a una experimentación empírica que invalida progresivamente la respuesta biomédica. Frente a la primera constatación de los síntomas, se acude al hospital en búsqueda de la adecuada respuesta terapéutica. Experimentadas sus (supuestas) limitaciones, se generan respuestas extra-biomédicas. Las siguientes veces, se elude el paso por el hospital. La estabilización de la respuesta terapéutica se fragua en base a mecanismos de ensayo error antes que en una representación a priori de la enfermedad.

\section{Construcción social del éxito y fracaso terapéutico y otras ventajas com- parativas}

La escasa relevancia del significado del choga responde a la sistematización de un dispositivo terapéutico (variable desde el punto de vista medicamentoso, aunque unitario desde el punto de vista de las representaciones,) percibido como eficaz, es decir que no deriva en la muerte o sufrimiento manifiesto del infante, y capaz de solventar por completo el desorden fisiológico observado. Si bien desde la perspectiva antropológica no corresponde valorar las (supuestas) limitaciones de los tratamientos biomédicos y (posible) eficacia de los tratamientos endógenos del choga, si cabe recalcar que la percepción de éxito o fracaso son, aunque basados en hechos empíricos, un constructo social.

La persistencia de los síntomas pasados los primeros días de tratamiento biomédico propicia la percepción de ineficacia de los mismos, menoscabando la confianza en la experticia médica. La falta de información en los espacios de 
consulta acerca de los efectos esperados y tiempo de remisión de los síntomas no son ajenos a la producción de esta lectura. En muchos casos, los facultativos ni siquiera comunican al enfermo y/o acompañantes el diagnóstico establecido, ciñéndose a la entrega de la receta (Jones Sánchez, 2014).

La interpretación en términos de ineficacia del tratamiento también es alentada por la supuesta rapidez de acción prestada a los "medicamentos de hospital". Magdalena abandonó al cabo de 7 días el tratamiento recetado en el hospital. Una amiga de su madre, a la vista de los síntomas le dijo que era choga, recomendándole visitar tía Mari, "una mujer ndowé [que] vive en los Cocos". Siguió con "Tía Mari" un tratamiento a base de plantas durante un mes. Magdalena acudía semanalmente a recogerlo, y lo aplicaba varias veces al día a su hijo mediante baños y lavativas según las indicaciones recibidas. Preguntada sobre el tiempo otorgado a cada procedimiento terapéutico, Magdalena explica:

"Porque el medicamento del hospital, no son igual de tradicional. Porque las medicinas del hospital ¿̨no? Una vez tienes fiebre lo tomas al instante, te cambia, pero la medicina tradicional te entra poco a poquito; te va entrando. No es tanto como medicamento del hospital. Si tú vas al hospital ahora, te ponen el suero, te mejoras al instante, pero nuestros medicamentos tradicionales no son así. Será un tiempo, a medida que estarás tomando, es cuando entra bien." (Magdalena, Ndowé, 20 años, un hijo)

Tanto la ausencia de pedagogía sanitaria en el espacio de la consulta, que permitiese una mayor comprensión de los efectos fisiológicos esperados (y adversos) del tratamiento recetado, como la valoración diferencial de los procedimientos terapéuticos determinan las percepciones de éxito o fracaso asociados a cada uno.

Por otra parte, la proximidad de la atención también oferta otras ventajas comparativas. Una vez descartado el recurso biomédico, más de la mitad de los casos son atendidos en el ámbito familiar o vecinal. Esta proporción aumenta en función de la edad y experiencia de la madre. La gestión del choga desde el entorno asegura un seguimiento cercano. Facilita, especialmente para las madres menos experimentadas, la resolución inmediata de dudas y preocupaciones relativas a la evolución de la enfermedad y a la desaparición más o menos lenta de 
los síntomas. Requiere en el hospital un nuevo desgaste de tiempo y dinero (transporte, tiempos de espera y consulta ${ }^{243}$ ).

Este último criterio de valoración es puesto de relieve por Rosario. Es una madre experimentada de 45 años. Tiene 10 hijos, seis de ellos y tres nietos viven con ella. Fue su cuñada, "la mujer de [su] hermano mayor" quién le enseño a tratar el choga.

"Ahí me dijo como tú tienes tanta familia, cuando no tienes dinero tu lo puedes hacer, y eso me ha ayudado varias veces, hasta lo he hecho a mis amigas también”. (Rosario, fang, 45 años, 10 hijos)

A diferencia de muchas mujeres, Rosario considera que el choga también puede curarse en el hospital y en algunas ocasiones ha recurrido al mismo. Partiendo de la misma interpretación de la enfermedad, activa mecanismos de respuesta diferentes según determinantes contextuales, económicos en algunos casos, pero también ligados a la percepción de gravedad y manifestación de otros síntomas añadidos, que no se integran en el cuadro clínico del choga.

\section{PERSPECTIVAS SOBRE CHOGA DESDE EL SECTOR SANITARIO}

La actitud activa de los individuos y colectivos frente al choga, permite generar saberes para su identificación, designación y catalogación; asimismo, da pié a la elaboración de un propio análisis de riesgo que sitúa los servicios sanitarios como una respuesta inapropiada e incluso en ocasiones peligrosa; finalmente, permite la producción de respuestas terapéuticas populares. El caso del choga muestra que la evolución y transformación de los saberes populares no se pueden desvincular de la relación que los agentes sociales mantienen con las instituciones sanitarias. No se gestan al margen sino en el marco de esta interacción. Su constitución resulta de un proceso de negociación y reapropiación selectiva con los saberes médicos que se manifiestan en consonancias y disonancias con los discursos sanitarios sobre el choga que analizamos a continuación.

243 El cuadro sintomatológico del choga se trata en consulta externa, al menos que vaya acompañado de otros síntomas asociados por ejemplo al paludismo o a la deshidratación situaciones frecuentes y que suelen requerir el ingreso del niño. 
De cara a entender mejor los desencuentros con las instancias sanitarias en torno a este proceso patológico infantil, se entrevistó a diferentes profesionales del sector salud. Desde este ámbito, también se generan diferentes perspectivas sobre el choga. Si bien tienden a distanciarse y enfrentarse con los discursos populares, muestran entre sí escasa homogeneidad. Médicos guineanos y expatriados, asistentes técnicos sanitarios (ATS), enfermeras y auxiliares de enfermería desarrollan discursos diferentes de acuerdo, no solo con los saberes de cada cual, sino también en consonancia con el estatus social que estos les otorga, y que condiciona los procesos de identificación/diferenciación con el enfermo y su entorno.

\section{La perspectiva del personal sanitario expatriado o la irrelevancia de las representaciones populares}

No se ha registrado, (con una salvedad que detallaremos más adelante,) ningún sanitario expatriado que conociese el término y significados asociados al choga. Religiosas españolas y médicos cubanos, principales actores expatriados involucrados en la asistencia directa a los pacientes, comparten el mismo desconocimiento, independientemente de su recorrido en el país ${ }^{244}$. Una religiosa espańola, enfermera, destinada al centro de salud de $\mathrm{M}^{\mathrm{a}}$ Gay, en Guinea desde 18 ańos, comenta al respecto:

"No sé nada de esa enfermedad, pero sí que es verdad que siempre vienen hablando de brujería. Eso aquí todavía pesa mucho" (Religiosa española, enfermera en el centro de Salud de $\mathrm{M}^{\mathrm{a}}$ Gay en Bata).

El discurso de la religiosa revela la percepción distorsionada de las categorías nosológicas y etiológicas locales, destacando la preeminencia exclusiva de su carácter sobrenatural. Asimismo, pone de manifiesto las modalidades de comunicación excluyentes que rigen el encuentro con el paciente. La interacción se cińe por parte de los facultativos a la selección de los elementos discursivos de los pacientes "pertinentes", esto es, relativos a los síntomas. Se eluden las informaciones que no se ajustan a los parámetros establecidos para elaborar el diagnóstico. Cualquier elemento fuera de estos cauces, no es considerado relevante, y por lo

244 Se entrevistó a dos médicos cubanos y 5 religiosas españolas. Los primeros no suelen pasar más de dos años en el país. Algunas religiosas españolas sin embargo llevan más de 20 años en Guinea Ecuatorial. 
tanto no se registra. El personal sanitario expatriado, religioso o no, desconoce, con raras excepciones, los saberes, prácticas y representaciones locales, ligadas a la enfermedad. La premisa de partida asume que son erróneos e infundados, y que su consideración no es por lo tanto necesaria para el desempeño de su labor.

Una enfermera española, laica, trabajando en el hospital privado La Paz de Bata que además mantenía el afán de realizar un "estudio antropológico acerca de la percepción fang de la enfermedad", expresa con crudeza, una perspectiva aún influyente entre sanitarios expatriados. Aseguraba que las prácticas y representaciones de los fang sobre la enfermedad estaban "ancladas en el neolítico"....

\section{La perspectiva de los médicos guineanos sobre al choga: la inoperancia del choga como diagnóstico}

Se entrevistó a tres jóvenes médicos guineanos en el servicio de pediatría del Hospital General de Bata. Ellos sí conocen el término y concuerdan en el uso frecuente que del mismo hacen las madres en el marco de la consulta.

"La gente dice eso de choga. Yo no sé lo que es eso. Yo no puedo decir choga porque no sé lo que es. La ciencia no conoce eso de choga. A veces esas diarreas pueden ser provocadas por los pañales; también se puede tratar de diarreas micóticas. Hay que hacer un análisis perianal [...]. Micostatin previene eso. Para tratarlo puedes utilizar micostatin, en jarabe, por vía oral y en pomada." (Médico 1, pediatra en el Hospital General de Bata).

"Cuando hablan de choga, la gente habla con mucha ignorancia. Podría ser una diarrea micótica. Una diarrea puede ser vírica, o infecciosa o parasitaria... Los curanderos actúan cortando la diarrea en un día o dos. No actúan en las causas." (Médico 2 pediatra en el Hospital General de Bata).

"EL problema del choga es que se van a las curanderías. Lo que llaman cho$g a$ puede ser muchas cosas. Lo que pasa es que ellos no saben. Una infección intestinal por ejemplo. Cuando no hay diarrea, se puede tratar con micostatine. Cuando hay diarrea lo primero es antibiótico para cortar la diarrea. En las curanderías lo tratan con lavativa, lavativa, y cuando hay diarrea solo puede empeorar la situación”. (Médico 3, pediatra en el Hospital General de Bata). 
El discurso de los tres médicos alude sistemáticamente a la valoración, negativa, de los comportamientos de la población frente a la enfermedad; comportamientos que por otra parte asocian estrechamente a las "curanderías" y "curanderos" lo que denota el desconocimiento de las prácticas domésticas puestas en marcha frente al choga, y el carácter biomédico de los principales agentes activos utilizados (y riesgos asociados). Subyace el anhelo frustrado de incidir plenamente en las decisiones e itinerarios de los pacientes, quienes rehúsan, especialmente en el caso del choga, el gobierno sanitario de los cuerpos.

Otro aspecto en el que inciden los tres testimonios, son las múltiples acepciones que podría tener el choga desde el punto de vista clínico, lo que supondría su inoperancia en términos diagnósticos. Erigiendo los síntomas diarreicos como la principal caracterización del choga, su "traducción" al lenguaje biomédico reviste un amplio espectro de patologías (infección intestinal, diarreas micóticas de carácter viral, infeccioso o parasitario), que contrastan con la precisión del cuadro popular. En definitiva, los tres entrevistados destacan la inoperancia del choga en términos clínicos, y si bien lo escuchan con frecuencia en boca de sus pacientes (a diferencia de los sanitarios expatriados quienes probablemente no lo oigan,) se resisten a utilizarlo. Se muestran más bien irritados por su uso que consideran inapropiado. La cuestión subyacente es la siguiente: ¿quién es legítimo para nombrar la enfermedad? Se espera del paciente que proceda a una descripción de los síntomas, y del terapeuta, que opere la interpretación de los mismos reagrupándolos en una entidad nosológica determinada. La nominación (popular en este caso) del padecimiento por parte del paciente (o su madre en referencia al choga) usurpa el rol del terapeuta. La competencia de la nominación, la responsabilidad del diagnóstico es un atributo del terapeuta. El diagnóstico y tratamiento del choga desde los saberes populares pone en tela de juicio la función social del médico. La retórica basada en la ignorancia de las madres, recurrente en los tres testimonios pretende desacreditar su capacidad para identificar, designar y catalogar una patología, y mantener el médico en su estatus social.

\section{El choga como diagnóstico: la perspectiva de los asistentes técnicos sani- tarios (ATS)}

Los ATS ocupan un lugar especialmente relevante en el sistema sanitario del país. Formados a finales de los ochenta y principio de los noventa por la cooperación española, aseguran la dirección y atención al paciente en los centros de salud 
del país, mientras que los médicos son asignados a los hospitales. Se registran las mismas recurrencias en torno a la ignorancia de las madres en los discursos de los ATS. Introducen no obstante dimensiones inexistentes en la perspectiva de los médicos. Destacan en primer lugar una reflexión mucho más aguda acerca de las prácticas terapéuticas populares actuales, y de las lógicas que presiden a su implementación:

"Hoy día, un recién nacido de unos días le ponen lavativa...dicen que ya tienen choga. Que choga es candidiasis intestinal. Muchas veces cuando hago la consulta de pediatría muchas veces me enfado. Sobre todo con las mujeres que ya tienen edad como yo. Porque tradicionalmente un niño pequeñito no se le puede poner una lavativa. ¿Qué es lo que le hacen? [...] El niño recién nacido puede defecar 14 veces al día que no es una diarrea. Cuando ven que el niño defeca así, y que la caca tiene que ir cambiándose, día a día, cuando ven eso: ¡Enfermedad! ¡Venga! Empiezan a darle lavativa. Lavativas que lo pones a un a mayor, este mayor sufre. Cuanto más un niño pequeñito. Te lo traen en el hospital, ya con un vientre así, con una diarrea que no veas. Al fin y al cabo, el niño acaba muriéndose. ¿Por qué? Porque están acaparando....ni tocan la tradición, ni miran la ciencia, ni miran nada. Esto es estupidez. Esto es lo que pasa ahora”. (ATS 1 en un centro de salud de Bata)

La correspondencia del choga con la candidiasis ha sido relevada en varias ocasiones entre los ATS. Asimismo, las causas identificadas como productos exógenos son aquí aún más explícitas que en los discursos populares:

"Es candidiasis. ¡Aquí fíjate! Aquí ponen a los niños pañales con polvo. El polvo es irritante. Polvo con pis, el niño termina de...hmhmh. Cuando lo ven ya dicen que la enfermedad llega. Encuentro que hay mucha ignorancia”. (ATS 2 en un centro de salud de Bata).

"No sé si el guineano o el africano, siempre quiere adoptar más lo moderno, sin considerar cuales son los por y los contras. A parte de que la misma enfermedad existe. De poner esos pañales de un solo uso, no miran que tienen un límite y que hay que cambiarlo. A veces tú ves a un niño que se lo han puesto desde la mañana, puede llegar hasta la tarde. Si no ha hecho cacá no se lo cambian. Si hace pis, va a hacer pis, y se olvidan que eso es un plástico. Todo ese calor no tiene como salir, y va a calentar el cuerpo del niño. Y derivará en otros problemas de salud que quizás el niño no podría haber tenido. Porque el pañal tradicional nuestro, el de tela, el niño transpira [...] no producía ese calor. Entonces yo creo 
que también es por... Por eso se produce tanto" (ATS 3 en un centro de salud de Bata)

Las causas del choga (el uso inapropiado de los pañales y de los polvos de talco en el cuidado de los niños) son claramente delimitadas. La percepción de una etiología específica ligada al choga conlleva su validez y utilización como categoría nosológica operativa. Es una postura radicalmente opuesta a la anterior. De las múltiples traducciones contempladas por los médicos, el choga adquiere aquí un sentido unívoco. Se establece una correspondencia estable entre significante y significado. Dos de las tres ATS entrevistadas realizan una traducción sistemática y directa entre las categorías populares (choga) y biomédicas (candidiasis) de designación de la enfermedad. Algunos de sus pacientes confirman que a diferencia de los médicos emplean el término en el marco de la consulta. La confirmación de la nomenclatura popular otorga al paciente la garantía de una buena comprensión de la enfermedad y confiere mayor legitimidad al tratamiento recetado ${ }^{245}$.

La percepción del choga desde el punto de vista de los médicos y ATS responde a itinerarios formativos y profesionales distintos. Los ATS han sido formados por la cooperación española entre finales de los ochenta y principio de los noventa con el afán de que puedan, más allá de la asistencia médica, llevar a cabo la gestión de un centro, procedimientos diagnósticos comunes y recetar en consonancia. Tras la salida de los médicos espańoles en 1994, han sido los principales actores de la atención sanitaria en el país desempeńando las funciones del médico, pero sin gozar de las ventajas salariales y del estatus asociado. Trabajan en la actualidad en los centros de salud, mientras los médicos están destinados a los hospitales. Estos últimos tienen un recorrido radicalmente diferente. La primera promoción de médicos guineanos licenciados en la universidad nacional del país es de 2006. Son por lo tanto relativamente jóvenes y poco experimentados. Asimismo, el último año de carrera se realiza en Cuba propiciando su descontextualización al regresar a Guinea. Si desde el punto de vista formativo los médicos reivindican la especificada y profundidad de su saber biomédico, los ATS apelan a su experiencia y mayor adecuación de sus conocimiento al contexto guineano.

245 Sería ciertamente interesante observar el grado de observancia del tratamiento en función de quien lo recetase, y del conocimiento y empleo, o no, de la nominación popular. 


\section{Enfermeras y auxiliares de enfermería}

La lectura heterogénea del choga también queda reflejada en la postura de algunas enfermeras y auxiliares de enfermería del Hospital General de Bata. Según los testimonios recogidos, comparten la perspectiva popular sobre la enfermedad.

"Según nuestra ciencia del hospital....casi no sé. Porque yo veo que actualmente todos los niños nacen con el choga. Es una infección intestinal [...]. Se producen por las infecciones de las madres, se producen....o sea no se de verdad". (Enfermera 1, Hospital General de Bata)

"El hospital calma pero no termina allí. Allí es calmante. De no ser que el choga va acompañado de la diarrea, casi no pasaría por el hospital. Porque suele haber de que el choga empiezas con la diarrea, y sabes que la diarrea es [...] alto riesgo. Porque es muy fácil matar. Y así se lleva a niños antes al hospital a recuperar fuerza, rehidratación y todo eso. Pero nunca acaba allí. Se va a reducir un poco con los antibióticos y esos antibióticos no son potentes para el choga". (Enfermera 2, servicio de pediatría del Hospital General de Bata)

Algunas enfermeras del hospital, al igual que muchas madres, reconocen desconocer las causas del choga. En el primer testimonio, si bien es catalogado como una "infección intestinal", no resulta suficiente como explicación etiológica. Otras enfermeras aluden también a los pañales y polvos de talco. En todo caso, prevalece la convicción de la insuficiencia de la respuesta biomédica: "calma, pero no cura". Numerosas madres relatan como frente a la persistencia de los síntomas, han sido las propias enfermeras quienes han postulado la hipótesis del choga, sugiriendo la necesidad de "ir a ver en fang".

\section{La dimensión social de las perspectivas del sector salud}

Se aprecia una graduación de las posturas en el propio cuerpo sanitario en función de la mayor o menor identificación con las personas ajenas al sector biomédico y en correspondencia con el estatus social asociado a cada escalón de la jerarquía profesional. Una graduación que abarca tanto la negación de la realidad social y nosológica del choga, como las consonancias con las representaciones populares sobre la enfermedad. En un extremo se sitúan los sanitarios expatriados 
para los que las representaciones populares son irrelevantes, y los médicos guineanos para los que estas sedimentan las resistencias a la implantación y desarrollo de la biomedicina. En el otro, la perspectiva de las enfermeras y auxiliares de enfermería se mimetiza en gran medida con las representaciones populares de la enfermedad. A medio camino, los ATS, si bien reprochan las deficiencias de las madres en el cuidado de sus hijos, convalidan al mismo tiempo la operatividad en términos diagnósticos del choga.

El acto diagnóstico no solo conlleva la identificación de una patología. Participa de los mecanismos de diferenciación en el seno de un mismo cuerpo profesional (Jaffré et Olivier de Sardan, 1995:780). Las diferentes posturas no solo se arraigan en un conocimiento corporativo diferente de la enfermedad ligada a un recorrido formativo de unos y otros. En el campo de la salud, los saberes son movilizados de forma estratégica, para generar, alimentar y reproducir relaciones de poder. Bajo cada perspectiva, subyace la posición social que otorga este saber, y la afirmación de una relación determinada con la población y el resto del cuerpo sanitario. El enunciado de la enfermedad recuerdan Jaffré y Olivier de Sardan, que de acuerdo con el ideal biomédico implica la existencia exclusiva de la perspectiva biologista de la enfermedad (desease), en detrimento de la realidad social (sickness) o individual (illness), adquiere inmediatamente una dimensión social, dependiendo de quién lo formule, incluso desde el propio sector sanitario (Jaffré y Olivier de Sardan; 1995: 780;781) ${ }^{246}$.

Paradójicamente, las representaciones populares presentan aparentemente mayor estabilidad que los discursos generados en el sector sanitario. La incapacidad de construir un discurso unitario y estable sobre el choga traduce la fragilidad material y organizativa del sistema sanitario guineano. Un sistema cuyas prioridades son además marcadas desde fuera, desde la nebulosa desarrollista, y que tienden a privilegiar problemas globales de salud (paludismo, VIH/Sida, tuberculosis etc.) en detrimento de las formulaciones y manifestaciones locales de la enfermedad. Las voces emitidas desde el sector salud no restringen sino que alimentan la polisemia del choga. También participan de la desorientación de los agentes sociales y de la incertidumbre en torno a la respuesta biomédica. Las dudas emitidas por algunos entrevistados así lo manifiestan:

246 Los autores recogen aquí las tres dimensiones de la enfermedad acuñadas por Kleinman (1978). 
"No decimos que el hospital no se cura o no. Solo queremos saber si el hospital se cura eso o no. Porque eso tenemos dudas. Gente que dice que eso se cura solamente en fang. Queremos saber si lo cura el hospital o no" (Clara, 31 años, fang, 3 hijos)

"Pero.... ¿Se puede tratar en el hospital? Usted también nos puede aconsejar" (Cecilia, fang, 32 años, 4 hijos).

\section{Conclusiones: ¿̨Posibles consonancias?}

Queda por relatar el discurso excepcional de un médico español, con un recorrido profesional no menos excepcional en Guinea Ecuatorial. R.S.E. es uno de los médicos emblemáticos de la intervención sanitaria de la cooperación espańola durante los años ochenta. Ha trabajado en el país durante casi treinta años. Llegó a principios de los ochenta, y ha sido uno de los principales impulsores de la Estrategia Nacional de Atención Primaria de Salud. Habla además el fang con fluidez, lengua mayoritaria en la zona de estudio. Este hecho es especialmente relevante, no solo por la escasez de expatriados que lo hablan, sino para el propósito desarrollado aquí.

Acudí a R.S.E. tras haber discurrido entre las diferentes voces, profesionales y populares del choga. Según relató, fue él quien "descubrió” el choga en Mongomo a mediados de los ochenta. Llegó incluso a ser conocido por la población en aquella zona como "el médico que curaba el choga" (hecho que pudimos comprobar con otros interlocutores). Según sus observaciones, se trataría de "candidiasis oral", "con diarrea crónica y pérdida de peso, propiciada por una situación de deficiencia inmunológica en la que suben los hongos". El tratamiento que solía aplicar, era nistatina ${ }^{247}$.

247 Tras la lectura del borrador del presente artículo, el médico español recalcaba que el uso frecuente desde las instancias sanitarias de antibióticos para el tratamiento de la diarrea no está exento de posibles efectos adversos. La administración oral de antibióticos elimina la flora intestinal, favoreciendo la aparición de hongos y una posible candidiasis digestiva. 
R.S.E.es el origen probable de ciertos elementos que componen los discursos sanitarios actuales en torno a la etiología del choga; especialmente de aquellos generados por los ATS, quienes, formados por la cooperación sanitaria española, lo asocian sin dudar a la candidiasis digestiva. Su "hallazgo" radica en la atención especial prestada a la formulación social de una enfermedad, tarea para la cual el uso de la lengua vernácula era imprescindible. Esta disposición epistemológica, poco frecuente entre médicos en general y expatriados en particular, participó indudablemente de la legitimidad terapéutica y reconocimiento popular alcanzado por el médico español. Pero R.S.E. no "descubrió" el choga. Si bien estableció algunas pautas que facilitasen su aprehensión desde el sector biomédico, quienes lo descubrieron fueron aquellos que en base a la observación de la aparición de determinados síntomas, elaboraron una descripción clínica que denominaron choga.

La deserción sistemática de los servicios sanitarios institucionales frente a cuadros clínicos tan específicos como el choga y completamente desvinculados desde las perspectivas populares de cualquier manifestación sobrenatural, invita necesariamente a cuestionarse sobre los motivos y modalidades del desencuentro entre la población y el cuerpo sanitario. Las disonancias no radican tanto en interpretaciones etiológicamente incompatibles. La lectura popular del choga no moviliza para su explicación la alteración del orden social y/o acciones perpetradas por entidades ocultas, que por esencia invalidarían la respuesta biomédica. En muchos casos, ni tan siquiera existe un discurso etiológico popular. El argumento cultural, alzado con frecuencia para dar cuenta de los comportamientos frente a la enfermedad y especialmente de las resistencias, recelos o incumplimiento de la población respecto a las directrices de las instancias sanitarias, es sino erróneo, al menos insuficiente. Asimismo, el caso del choga muestra que la evolución y transformación de los saberes populares relativos a la salud y a la enfermedad, no se pueden desvincular de la relación que los agentes sociales mantienen con las instituciones sanitarias. No se gestan al margen sino en el marco de esta interacción.

Según sus observaciones, el choga aparecería muchas veces tras el tratamiento con antibióticos orales. Esta lectura alumbra desde otra perspectiva la aprehensión popular de las instancias sanitarias como un factor de riesgo en relación con el choga. En relación con los tratamientos populares, R.S.E. indica que el uso de la tetraciclina por vía oral debería por los mismos motivos empeorar la infección. No obstante, la aplicación en lavativa, si bien no debería afectar la flora intestinal, no tendría a su juicio, ningún efecto sobre el choga. 
Frente a la supuesta ignorancia de la población argüida por los terapeutas biomédicos, las madres alegan el carácter no concluyente de las soluciones proporcionadas por las instancias sanitarias. Permanece un descrédito mutuo sobre los respectivos mecanismos de respuesta que impide un consenso sobre la eficacia de los tratamientos.

La idoneidad del itinerario y elección de los recursos terapéuticos que constituyen en el caso del choga el principal punto de discordancia, responde por parte de las madres, a un proceso empírico de experimentación que no se puede leer exclusivamente en términos culturales. Lejos de una entrega pasiva de los cuerpos, los individuos y colectivos, acostumbrados a lidiar con los disfuncionamientos cotidianos de un sector salud especialmente precario, elaboran saberes y estrategias que no deshabilitan los recursos institucionales, pero sí propician su uso contextual y selectivo (Jones Sánchez, 2014). La producción de respuestas terapéuticas endógenas, generalmente domésticas, que responden a las expectativas de eficacia, resulta más abordable desde el punto de vista económico, y más práctico desde el punto de vista del seguimiento. Propicia la intervención y participación del entorno cercano del niño. Permite asimismo paliar las dificultades de acceso a las estructuras de salud, (en términos económicos, de tiempo y distancia,) y las interacciones someras y abruptas del espacio de consulta que desatienden las expresiones locales de la enfermedad y excluyen dinámicas didácticas respecto al diagnóstico y tratamiento.

Como señalan Jaffré y Olivier de Sardan, la existencia social de la enfermedad, es decir las modalidades bajo las cuales es vivida, percibida, y nombrada por los individuos y colectivos, permanece ausente de los programas de educación para la salud (Jaffré et Olivier de Sardan : 774). También de los espacios de consulta. R.S.E. por su parte, atento a las formulaciones locales, ha reforzado su legitimidad y poder terapéutico. 


\section{Fuentes Bibliografícas:}

Augé, M., \& Herzlich, C. : Le sens du mal, anthropologie, histoire, sociologie de la maladie, Paris, Ed. des Archives contemporaines, 1984.

BIBEAU,G. : "L'organisation Ngbandi des noms de maladies " en Anthropologie et Sociétés, vol. 2, n 3, pp. 83-116, 1978.

Fundación de Religiosas para la Salud (FRS): Manual de Plantas Medicinales para Guinea Ecuatorial. Creación y Coordinación: LOPEZ SERRANO, M. 1ª Edición, mayo 2012.

Gillies E.: "Causal criteria in African classifications of disease" en J.B Loudon (coord.), Social anthropology and medicine, Ed. London, Académie Press, pp.358-395, 1976.

Gomez Marín, E. y Merino Cristobal, L.: Plantas medicinales de Guinea Ecuatorial, Centro Cultural Hispano-guineano Ediciones, 1990.

Jaffré, Y. : «Pharmacies des villes, pharmacies "par terre" », en Bulletin de l'APAD no 17 , 1999. Consultado el 2 de abril de 2012 en http://apad.revues.org/482

Jaffré, Y., y Olivier de Sardan, J.-P. : "Tijiri, la naissance sociale d'une maladie " en Cahiers des Sciences Humaines, no31, 4, p. 773-795, 1995.

Jones Sánchez, A.: "Saberes, percepciones y modalidades de uso de los recursos terapéuticos en Bata, guinea ecuatorial", en Aranzadi Martinez J. \& Moreno Feliú, P. (coord.), Perspectivas Antropológicas sobre Guinea Ecuatorial, pp. 101-134, 2014.

Kleinman, A.: "Concepts and a mode1 for the comparison of medicals systems", en Social science and medicine, $\mathrm{n}^{\circ} 12$ pp. 85-93. 1978.

Mallart-Guimera, L. :"La classification Evuzock des maladies", en Journal des Africanistes, no47,1, pp.9-51, $1977 \mathrm{a}$.

Mallart-Guimera, L. :"La classification Evuzock des maladies", en Journal des Africanistes, 2, pp.9-47,1977b.

Mallart-Guimera, L. : Ni dos ni ventre, Nanterre, laboratoire d'ethnologie et de sociologie comparative de Paris X. 1981.

Massé, R. : «La place des savoirs populaires face aux savoirs savants en contexte de pluralisme thérapeutique», Revue internationale sur le médicament, 2006. Consultado el 1 de julio de 2014 en http://www.geirsomedicaments.uqam.ca/revue_RIM/ RIM2/PDF/RIM2-2-Masse14-49.pdf

Menéndez, E.: "La enfermedad y la curación: ¿Qué es medicina tradicional?", en Alteridades. Año 4, N7, UAM-Iztapalapa, México, 1994.

Monteillet, N. :Le pluralisme thérapeutique au Cameroun. Crise hospitalière et nouvelles pratiques populaires, Karthala, Paris, 2005. 
Nieto Olarte, M.: "Remedios para el imperio: de las creencias locales al conocimiento ilustrado en la botánica del siglo XVIII" en Obregon, D., Culturas Cientificas y saberes locales, Bogotá, Universidad Nacional de Colombia. pp.89-102, 2000.

Touré, L.: "Une innovation sanitaire: l'appropriation des médicaments par les populations touaregs du Mali ", en Pordié, L. (ed.), Penser le monde, penser les médecines, Traditions médicales et développement sanitaire, pp. 269-286, Paris Karthala, 2005.

Sturzenegger Odina : Le Mauvais ail de la lune. ethnomédecine créole en Amérique du Sud. Karthala, Paris 1999. 
